\title{
Analysis on the Influencing Factors of Farmers' Family Operating Income in Heilongjiang Province ---Based on Multiple Linear Regression

\author{
Lou Sha
}

Harbin University of Commerce, Harbin China 150028

lousha1983@163.com

Keywords: Family operating income; Influencing factors; Multiple linear regression; Micro perspective

\begin{abstract}
Farmers' income in Heilongjiang mainly comes from family operating income, so it is necessary to study the influencing factors of family operating income. The paper, using the research data and constructing the multiple linear regression models, studies the key influencing factors of farmers' family operating income from the micro perspective. The paper arrives at the conclusion that the capital investment, land operation scale, the cultural quality of labor force, the agricultural power and the scientific farming play a major role in promoting family operating income.
\end{abstract}

\section{Introduction}

There are many factors that influence the family operating income, such as the amount of capital investment, the land scale, the land quality, the characteristics of labor force, the level of technology, the application of science and technology and the degree of organization [1]. Using the survey data, the paper analyzes the impact of individual differences on family operating income and finds out the key factors to promote income growth.

\section{Model Selection}

In this part, the main objective is to find the main influencing factors of family operating income and it involves more types of factors, so it is suitable for multiple linear regression model to analyze. The specific model is as follows:

$$
Y=C+\beta_{1} X_{1}+\beta_{2} X_{2}+\ldots \ldots+\beta_{n} X_{n}+\varepsilon
$$

$\mathrm{Y}$ is the increment of the farmer's income, $\mathrm{C}$ is the constant term, $\beta \mathrm{n}$ is the regression coefficient of the corresponding variable, $\mathrm{Xn}$ is the corresponding variable, $\varepsilon$ is the random disturbance term, $\mathrm{n}$ is in the range of 1 to 10 .

\section{Indicator Impact Assumptions}

The indicators have the impact on farmers' family operating income in Heilongjiang. Assumptions are as follows: 
Table 1 Assuming direction of model variables

Variable

Assuming direction

$\mathrm{X}_{1}$ (capital investment)

positive

$\mathrm{X}_{2}$ (land management scale)

positive

$\mathrm{X}_{3}$ (low - yield land scale)

negative

$\mathrm{X}_{4}$ (age of labor force)

uncertain

$\mathrm{X}_{5}$ (cultural quality of labor force)

positive

$\mathrm{X}_{6}$ (number of labor force)

positive

$\mathrm{X}_{7}$ (the agricultural power)

positive

$\mathrm{X}_{8}$ (mechanization rate)

uncertain

$\mathrm{X}_{9}$ (whether it is scientific farming)

positive

$\mathrm{X}_{10}$ (whether to join a cooperative)

positive

\section{Data Selection and Feature Analysis}

The data of this part are mainly collected from the survey data. The survey involves 431 questionnaires. The specific data are shown in the following table:

Table 2 The analysis of data

\begin{tabular}{crcccc}
\hline Item & \multicolumn{1}{c}{$\mathrm{N}$} & Minimum & Maximum & Mean & Std. Deviation \\
\hline $\mathrm{X}_{1}$ & 431 & 1250.00 & 222650.00 & 25617.8619 & 28609.89336 \\
$\mathrm{X}_{2}$ & 431 & .50 & 30.00 & 3.5278 & 3.15266 \\
$\mathrm{X}_{3}$ & 431 & .00 & 60.00 & 10.1531 & 6.33042 \\
$\mathrm{X}_{4}$ & 431 & 28.00 & 70.00 & 40.8360 & 6.36396 \\
$\mathrm{X}_{5}$ & 431 & 1.00 & 4.30 & 3.0320 & .67962 \\
$\mathrm{X}_{6}$ & 431 & 1.00 & 5.00 & 2.5824 & .74213 \\
$\mathrm{X}_{7}$ & 431 & .00 & 80.00 & 13.5777 & 15.16323 \\
$\mathrm{X}_{8}$ & 431 & .00 & 100.00 & 66.0209 & 31.71827 \\
$\mathrm{X}_{9}$ & 431 & .00 & 1.00 & .3202 & .46709 \\
$\mathrm{X}_{10}$ & 431 & .00 & 1.00 & .2251 & .41811 \\
$\mathrm{Y}$ & 431 & 4160.00 & 206150.00 & 23999.2401 & 25498.40228 \\
Valid N (listwise) & 431 & & & & \\
\hline
\end{tabular}

\section{Preliminary Results of the Model Analysis}

In the process of analysis using SPSS software, the paper estimates all the selected indicators through the multiple linear regression. The specific model analysis results are as follows:

From the fit point of view, $\mathrm{R}$ value is $0.866, \mathrm{R} 2$ is 0.750 , after adjusted $\mathrm{R} 2$ is 0.743 . The three values are greater than 0.7 , indicating that the model is a good degree of fitting, a better explanation of influencing effects from family operating income. In addition, from the F test point of view, $\mathrm{F}$ value is 96.45 , the sig. Value is 0.000 , indicating that the model passed the $\mathrm{F}$ test, refused to zero hypothesis. It is assumed that the relationship between the independent variable and the dependent variable in the model is linear. 
Table 3 Model Summary

\begin{tabular}{cccc}
\hline Model & $\mathrm{R}$ & R Square & Adjusted R Square \\
\hline 1 & $0.866(\mathrm{a})$ & 0.750 & 0.743 \\
\hline
\end{tabular}

Table 4 ANOVA (b)

\begin{tabular}{ccccccc}
\hline Model & & Sum of Squares & df & Mean Square & F & Sig. \\
\hline \multirow{2}{*}{1} & Regression & 209798472862.511 & 10 & 16138344066.347 & 96.45 & $.000(\mathrm{a})$ \\
& Residual & 69773990173.885 & 420 & 167323717.443 & & \\
& Total & 279572463036.396 & 430 & & & \\
\hline
\end{tabular}

Table 5 Coefficients (a)

\begin{tabular}{cccccc}
\hline \multicolumn{7}{c}{ Unstandardized } & Standardized \\
Coefficients & Coefficients & $\mathrm{t}$ & Sig. \\
& $\mathrm{B}$ & Std. Error & Beta & & \\
\hline (Constant) & -42319.37 & 9566.800 & & -4.424 & .000 \\
$\mathrm{X}_{1}$ & 0.167 & .075 & 0.187 & 2.217 & .027 \\
$\mathrm{X}_{2}$ & 4095.059 & 686.243 & 0.506 & 5.967 & .000 \\
$\mathrm{X}_{3}$ & -633.712 & 104.385 & -0.157 & -6.071 & .000 \\
$\mathrm{X}_{4}$ & 460.383 & 201.532 & 0.115 & 2.284 & .023 \\
$\mathrm{X}_{5}$ & 2814.370 & 1137.779 & 0.075 & 2.474 & .014 \\
$\mathrm{X}_{6}$ & 1370.412 & 1338.731 & 0.040 & 1.024 & .307 \\
$\mathrm{X}_{7}$ & 184.111 & 51.624 & 0.109 & 3.566 & .000 \\
$\mathrm{X}_{8}$ & -0.323 & 23.088 & 0.000 & -0.014 & .989 \\
$\mathrm{X}_{9}$ & 4152.004 & 1447.220 & 0.076 & 2.869 & .004 \\
$\mathrm{X}_{10}$ & 1500.040 & 1787.551 & 0.025 & 0.839 & .402 \\
\hline
\end{tabular}

According to the model result, we can see that X1, X2, X4, X5, X6, X7, X9 and X10 has a positive impact on family operating income. The influence coefficients are 0.167, 4095.059, 460.383, 2814.370, 1370.412, 184.111, 4152.004, 1500.040 respectively. Compared with the hypothesis, influencing direction of the above factors are basically the same as the direction of the assumptions. The assumptions are further verified. Among the positive factors, X1, X2, X4, X5, X7, $\mathrm{X} 9$, the corresponding sig. is $0.027,0.000,0.023,0.014,0.000$ and 0.004 , all less than 0.05 , X6 and $\mathrm{X} 10$, the corresponding sig. is 0.037 and 0.402 which are not tested by t test.

In addition, $\mathrm{X} 3$ and $\mathrm{X} 8$ has a negative impact on family operating income. The influence coefficients are -633.712 and -0.323 . Compared with the hypothesis, influences from X3 and X8 are basically the same as the direction of the assumptions. $\mathrm{X} 3$ and $\mathrm{X} 8$, the corresponding sig. is 0.000 and 0.989 . X3 is tested by t test and $\mathrm{X} 8$ isn't tested by $\mathrm{t}$ test.

\section{Model Optimization Analysis}

In order to further optimize the model, we can get rid of the index which is not passed, then carry out multiple linear regression and get the following conclusion:

From the fit point of view, $\mathrm{R}$ value is $0.848, \mathrm{R} 2$ is 0.718 , after adjusted $\mathrm{R} 2$ is 0.715 . The value of the three is greater than 0.7 , indicating that the optimization of the model after a good degree of fitting, a better explanation of influencing effects from family operating income. In addition, from the $\mathrm{F}$ test point of view, $\mathrm{F}$ value is 139.730 , its sig. value of 0.000 , indicating that the model passed 
the F test, refused to zero hypothesis. It is assumed that the relationship between the independent variable and the dependent variable in the optimization model is linear [2-4].

Table 6 Model Summary

\begin{tabular}{cccc}
\hline Model & $\mathrm{R}$ & R Square & Adjusted R Square \\
\hline 1 & 0.848 & 0.718 & 0.715 \\
\hline
\end{tabular}

Table 7 ANOVA (b)

\begin{tabular}{clrrrrr}
\hline Model & & \multicolumn{1}{c}{ Sum of Squares } & \multicolumn{1}{c}{ df } & \multicolumn{1}{c}{ Mean Square } & \multicolumn{1}{c}{ F } & Sig. \\
\hline \multirow{2}{*}{1} & Regression & 209453335539.393 & 7 & 23272592837.710 & 139.730 & $.000(\mathrm{a})$ \\
& Residual & 70119127497.002 & 423 & 166553747.024 & & \\
& Total & 279572463036.396 & 430 & & & \\
\hline
\end{tabular}

According to the model result, we can see that X1, X2, X4, X5, X7and X9 has a positive impact on family operating income. The influence coefficients are 0.177, 4068.880, 308.126, 2950.703, 16692.810, 188.643 and 4382.735. Compared with the hypothesis, influencing direction from X1, $\mathrm{X} 2, \mathrm{X} 4, \mathrm{X} 5, \mathrm{X} 7$ and $\mathrm{X} 9$ are basically the same as the direction of the assumptions. The corresponding sig. is $0.018,0.000,0.031,0.007,0.000$ and 0.002 , all less than 0.05 , indicating that they all pass the $t$ test.

In addition, X3 has a negative impact on family operating income [5]. The influence coefficient is -643.823. Compared with the hypothesis, influences from X3 is basically the same as the direction of the assumptions and its corresponding sig. is 0.000 , indicating that $\mathrm{X} 3$ passes the $\mathrm{t}$ test at a confidence level of 5\%. Finally, through the model simulation, we can draw the following equation:

$$
\begin{aligned}
& Y=-39394.89+0.177 X_{1}+4068.880 \mathrm{X}_{2}-643.823 \mathrm{X}_{3}+308.126 \mathrm{X}_{4}+2950.703 \mathrm{X}_{5} \\
& +188.643 \mathrm{X}_{7}+4382.735 \mathrm{X}_{9}
\end{aligned}
$$

Table 8 Coefficients (a)

\begin{tabular}{cccccc}
\hline \multicolumn{7}{c}{ Unstandardized } & \multicolumn{2}{c}{ Standardized } \\
Coefficients & t & Sig. \\
& $\mathrm{B}$ & Std. Error & & & \\
\hline Constant $)$ & -39394.89 & 8762.741 & & -4.496 & .000 \\
$\mathrm{X}_{1}$ & 0.177 & 0.075 & 0.199 & 2.374 & .018 \\
$\mathrm{X}_{2}$ & 4068.880 & 673.756 & 0.503 & 6.039 & .000 \\
$\mathrm{X}_{3}$ & -643.823 & 103.634 & -0.160 & -6.212 & .000 \\
$\mathrm{X}_{4}$ & 308.126 & 142.689 & 0.077 & 2.159 & .031 \\
$\mathrm{X}_{5}$ & 2950.703 & 1082.104 & 0.079 & 2.727 & .007 \\
$\mathrm{X}_{7}$ & 188.643 & 49.371 & 0.112 & 3.821 & .000 \\
$\mathrm{X}_{9}$ & 4382.735 & 1417.116 & 0.080 & 3.093 & .002 \\
\hline
\end{tabular}

\section{Conclusion}

From the final simulation equation, it can be seen that X2 (land management scale), X5 (cultural quality of labor force), and X9 (whether it is scientific farming) has a larger positive impact on family operating income, which is the main contributor to farmers' income growth [6-8]. When X2 
(land management scale) increases 1 hectare, the family operating income will grow 4068.88 yuan. When X5 (cultural quality of labor force) improves a level, it will grow 2950.703 yuan. When X9 (whether it is scientific farming) chooses the scientific farming behaviors, it will grow 4382.735 yuan. X1 (capital investment), X4 (age of labor force) and X7 (agricultural power) also play a certain role in promoting family operating income, but the influence is smaller [9]. When X1 (capital investment) increases by 1 yuan, the family operating income will grow 0.177 yuan. When X4 (age of labor force) increases by 1 year, it will increase by 308.126 yuan. When X7 (agricultural power) increases by 1 horsepower, it will grow 188.643 yuan.

In addition, X3 (low-yield land scale) has a restrictive effect on family operating income [10]. When X3 (low-yield land scale) increases by 1 unit, it will be reduced by 643.823 yuan.

\section{Acknowledgments}

The paper is funded by the National Social Science Fund General Project "Research on Rural Financial Service Innovation and Risk Control in the Background of Agricultural Land Reform" (16BJL037).

\section{References}

[1] Su Zhidong, Zhuang Jingyuan, Jiang Yong. Analysis the Influencing Factors of Farmers' Income in Fujian Province [J]. Science Innovation and Application, 2016, (36): 51-52

[2] Li Yiqing. A Quantitative Analysis of the Factors Affecting Farmers' Income in China [J] .Journal of Agriculture, 2016, (09): $1+11$.

[3] Dian Jie. An Empirical Study on the Factors Affecting Farmers' Income in Guangdong [J]. Modern Business, 2016, (17): 190-191.

[4] Du Xueru, Zhang Yarong. Analysis on the Gray Incidence of Farmers' Income in Yongchang County [J] .Gansu Agriculture, 2016, (11): 10-12.

[5] Li Xiaolong, Zheng Wei. The Theory, Empirical and Countermeasure of Influencing Factors of Farmers' Income [J]. China Agricultural Resources and Zoning, 2016, (05): 90-95.

[6] Yu Zhenwei, Duan Nanni. Empirical Analysis of Farmers' Income in Shandong Province factors [J] Shandong Agricultural University (Social Science Edition), 2016, (01): 48-52 + $116+126$.

[7] Wu Wei. A Study on the Influencing Factors of Farmers' Income in Inner Mongolia [J] .Journal of Cooperative Economy and Technology, 2015, (20): 14-15.

[8] Zhang Dehua. Financial support, scale management and farmers' income in Heilongjiang Province[M].Beijing: China Fortune Press,2015.

[9] Cai Feifeng, Jiang Sanliang. An Empirical Study on the Influencing Factors of Farmers' Income in China [J]. Journal of Anhui Agricultural Sciences, 2015, (01): 365-368.

[10]Bai Binfei, Hu Jinbang. Factors affecting the income of farmers in Sichuan Province [J] Chinese and foreign entrepreneurs, 2014, (23): 215-216. 